\title{
Rendimento de cultivares de brócolis semeadas em outubro na região centro do Rio Grande do Sul
}

\author{
Yield response of spring-sown broccoli cultivars in Southern \\ Brazil
Jorge Nadir Trevisan ${ }^{1}$ Gustavo Adolfo Klippel Martins ${ }^{2}$ Marion $^{4}$ Bruno Gennaro Trevisan ${ }^{5}$ \\ Alessandro Dal'Col Lúcio ${ }^{3}$ Cristiano Castaman ${ }^{4}$ Rubens Rafael
}

\section{RESUMO}

A temperatura afeta de modo diferente o desenvolvimento da planta, a diferenciação floral, o tamanho e qualidade da cabeça, a produtividade e a duração do ciclo hortícola de brócolis (Brassica oleracea L. var. italica Plenck). O uso de cultivares tolerantes a temperaturas altas permite a ampliação das regiões de cultivo, épocas de plantio e período de oferta do produto no mercado, além de aumentar a rentabilidade da cultura. Os objetivos deste trabalho foram avaliar o rendimento, ciclo hortícola e distribuição da colheita de oito cultivares de brócolis semeadas na primavera, na região central do Rio Grande do Sul. O experimento foi conduzido na Universidade Federal de Santa Maria, em solo Vacacaí. O transplante foi realizado em 20/11/1996, aos 24 dias após a semeadura, com população de 14.200plantas ha ${ }^{-1}$. As unidades experimentais de $9,80 \mathrm{~m}^{2}$ foram arranjadas em delineamento de blocos ao acaso com quatro repetições. Foram coletados dados de rendimento de cabeças centrais e ramificações laterais em intervalos de dois a três dias. Houve diferenças significativas entre cultivares para rendimento comercial de cabeças, ramificações laterais, e rendimento comercial total. $O$ rendimento de cabeças, principal componente do rendimento de 'Baron' e 'Hana Midori', foi significativamente maior que $o$ das demais cultivares. O rendimento de ramificações laterais foi o principal componente do rendimento total de seis cultivares. 'Piracicaba Precoce'e 'Piracicaba Precoce de Verão' apresentaram o mais alto rendimento de ramificações e diferiram significativamente entre si. O ciclo horticola foi, para todas as cultivares, em média, de 134 dias, e o periodo de colheita, de 37 dias. Houve acentuada variação entre cultivares para distribuição semanal dos componentes rendimento de cabeças e de ramificações laterais.

Palavras-chave: Brassica oleracea var. italica, época de plantio, produtividade, distribuição de colheita.

\section{ABSTRACT}

Temperatures affect differently plant development, floral differentiation, head size and quality, yield, and duration of hoticultural cycle of broccoli cultivars (Brassica oleracea L. var. italica Plenck). The use of cultivars tolerant to higher temperatures allows expanding growing areas, scheduling planting dates, broadening product marketing, besides increasing crop returns. The objectives of this study were to evaluate the yield, horticultural cycle and yield distribution throughout the harvest period of eight broccoli cultivars springsown in the central area of Rio Grande do Sul State, in southern Brazil. The experiment was carried out at the Federal University of Santa Maria on Vacacai soil. Twenty four-day-old seedlings

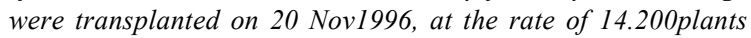
$\mathrm{ha}^{-1}$, to $9,80 \mathrm{~m}^{2}$ experimental units laid out in a randomized block design replicated four times. Data were collected for yield of marketable center and lateral heads harvested at 2-3

${ }^{1}$ Engenheiro Agrônomo, Especialista., Professor Adjunto, Departamento de Fitotecnia, Centro de Ciências Rurais (CCR) Universidade Federal de Santa Maria (UFSM), 97105-900. Santa Maria, RS. E-mail : trevisan@ccr.ufsm.br. Autor para correspondência.

${ }^{2}$ Engenheiro Agrônomo, Mestre, Professor Titular, Departamento de Fitotecnia, CCR, UFSM.

${ }^{3}$ Engenheiro Agrônomo, Doutor, Professor Adjunto, Departamento de Fitotecnia, CCR, UFSM.

${ }^{4}$ Acadêmico do Curso de Agronomia, CCR, UFSM.

${ }^{5}$ Acadêmico do Curso de Agronomia, CCR, UFSM. Bolsista do FIPE. 
day intervals. There were significant differences among cultivars for yield of marketable center and lateral heads and for total marketable yield. The yield of center heads, main component of 'Baron' and 'Hana Midori', was significantly higher than the remainder cultivars. The yield of lateral heads was the major component of total marketable yield for six cultivars. 'Piracicaba Precoce' and 'Piracicaba Precoce de Verão' were the highest-yielding cultivars for lateral heads, and both differered significantly. The horticultural cycle averaged 134 days, and the mean harvest period lasted 37 days for all cultivars There were marked differences among cultivars for weekly yield distribution of center and lateral heads.

Key words: Brassica oleracea var. italica, planting time, productivity, weekly yield distribution.

\section{INTRODUÇÃO}

A avaliação do potencial de cultivares em diferentes regiões agroclimáticas, além de proporcionar sustentabilidade a pesquisas subseqüentes, é imprescindível para o aumento da rentabilidade das culturas, o qual está diretamente relacionado ao uso de cultivares geneticamente superiores em termos de produtividade e outras características agronômicas relevantes (SANTA CATARINA, 2001).

Sendo o desenvolvimento de brócolis favorecido por clima predominantemente frio, plantios entre abril e junho permitem, no Paraná, colheitas desde julho até início de outubro, estando em andamento naquele Estado experimentos que visam à ampliação do período de colheita, nos períodos de abril a junho e nos meses de novembro e dezembro, com fins de produção de matéria-prima industrial (TOLEDO, 2001). A couve-brócolis cresce satisfatoriamente em diferentes partes do mundo, mas temperaturas acima de $30^{\circ} \mathrm{C}$ podem provocar deformação das cabeças em cultivares sensíveis a temperaturas altas, tornando a cultura de alto risco nessas condições (Björkman \& Pearson, 1998).

As exigências climáticas de brócolis, segundo THOMPSON \& KELLY (1959), FILGUEIRA (1982) e FERREIRA (1983) são as mesmas da couveflor, embora seja menos sensível que esta às temperaturas altas, podendo ser cultivado em locais onde a couve-flor não produz satisfatoriamente. McCOLLUM (1975) afirma que as exigências climáticas do brócolis são similares às do repolho.

A couve-brócolis requer clima ameno ou temperado, produzindo sob determinadas condições em climas mais quentes (CASSERES, 1980; FILGUEIRA, 1982; SONNENBERG, 1985). No Brasil, predominam as cultivares de outono-inverno, (FILGUEIRA, 1982; SONNENBERG, 1985), tendo sido selecionadas algumas cultivares para temperaturas altas
(GIORDANO, 1983), as quais possibilitam a ampliação das regiões de cultivo, épocas de plantio e período de oferta no mercado. De acordo com SILVA (1997), embora o plantio de verão seja menos produtivo, a rentabilidade do cultivo nessa época é favorecida por preços mais altos em virtude da colheita ocorrer no período de entressafra.

A incorporação genética de tolerância a temperaturas mais elevadas permite o cultivo também durante o verão (FILGUEIRA, 1982; SONNENBERG, 1985). A única cultivar de brócolis tropical, que se tem conhecimento no mundo, Ramoso Piracicaba de Verão, foi desenvolvida no Brasil. A emissão mais tardia da inflorescência central em cultivares adaptadas ao cultivo de inverno, como Ramoso Santana, comparativamente ao que ocorre com as cultivares de verão indica requerimento de temperaturas mais baixas para a diferenciação floral (ATHANÁZIO \& SILVA, 1985).

O crescimento e a qualidade das brassicáceas, segundo KNOTT (1962) e CASSERES (1980), são melhores com temperaturas médias de 15 a $18^{\circ} \mathrm{C}$ e máximas de $23,8^{\circ} \mathrm{C}$. De acordo com dados do INMET, coletados pelo Departamento de Fitotecnia da UFSM, durante o período experimental, de outubro de 1996 a fevereiro de 1997, ocorreu uma temperatura média de $23,0^{\circ} \mathrm{C}$, média das mínimas de $18,5^{\circ} \mathrm{C}$ e média das máximas, de $28,3^{\circ} \mathrm{C}$. Nos meses de dezembro e janeiro a média das máximas foi de $30,5^{\circ} \mathrm{C}$, que pode ser considerada alta para o bom desempenho agronômico desse cultivo. A temperatura média mensal para o desenvolvimento das brassicáceas varia de 15 a $20^{\circ} \mathrm{C}$ (FERREIRA,1983), sendo a temperatura ótima para o crescimento vegetativo poucos graus acima da ótima para o crescimento reprodutivo (UNIVERSITY OF CALIFORNIA, 1987).

Períodos prolongados de temperatura acima de $25^{\circ} \mathrm{C}$ podem retardar a formação da cabeça em plantas que se encontram em fase de crescimento vegetativo, enquanto que plantas com cabeças em formação podem reverter para crescimento vegetativo, reduzindo o tamanho das cabeças e causando desenvolvimento de folhas ou brácteas nos pedúnculos florais (UNIVERSITY OF CALIFORNIA, 1987). Por outro lado, elevações abruptas de temperatura podem provocar crescimento excessivamente rápido da cabeça e alongamento do pedúnculo em determinadas cultivares (UNIVERSITY OF CALIFORNIA， 1987; SONNENBERG, 1985). Durante o período de colheita, temperaturas altas aceleram o desenvolvimento de cabeças, dificultando sua colheita no estágio ótimo para comercialização (THOMPSON \& KELLY, 1959).

Em Brasília, MELO \& GIORDANO (1995) avaliaram híbridos comerciais e experimentais e 
obtiveram, para os mais produtivos, rendimento de 9,4 a $13,0 \mathrm{tha}^{-1}$ de cabeças e de 5,2 a 7,0t ha- em ramificações laterais. Dentre as cultivares e híbridos, estudados por LIRA FILHO et al. (1997), na Zona da Mata do Estado de Pernambuco, destacaram-se 'Ramoso Piracicaba', 'Hanamidori' e 'Legacy', com produções de $10,13 \mathrm{t} \mathrm{ha} \mathrm{h}^{-1}, 8,76 \mathrm{t} \mathrm{ha}^{-1}$ e $6,38 \mathrm{t} \mathrm{ha} \mathrm{h}^{-1}$, respectivamente.

Os objetivos deste estudo foram avaliar o rendimento de cabeças e ramificações comerciais, rendimento comercial total, rendimento total, duração do ciclo hortícola e distribuição do rendimento comercial durante o período de colheita de 8 cultivares de brócolis plantadas em outubro na região centro do Rio Grande do Sul, utilizando, para a cultivar Ramoso Santana, sementes de quatro procedências diferentes.

\section{MATERIAL EMÉTODOS}

O experimento foi realizado no ano agrícola de 1996, em condições de campo, no campus da Universidade Federal de Santa Maria (UFSM), localizada na região fisiográfica da Depressão Central do RS (latitude: $29^{\circ} 43^{\prime} \mathrm{S}$, longitude: 5342' W, altitude: $95 \mathrm{~m})$. O solo foi classificado como Planossolo Gley Pouco Húmico (BRASIL, 1973), unidade de mapeamento Vacacaí, de textura média (DALMOLIN \& KLAMT, 1997).

Utilizou-se o delineamento experimental de blocos ao acaso, com 11 tratamentos, representados pelas cultivares Ramoso Santana (Agroceres, Agroflora, Isla e Topseed); Piracicaba Precoce de Verão, Flórida, Condor (Agroflora) e Piracicaba Precoce (Isla), do tipo ramoso, e Green River (Isla); Baron, e Hana Midori (Sakata), do tipo cabeça central, de diâmetro variável, e quatro repetições. Cada unidade experimental foi constituída por 14 plantas, arranjadas em linhas simples, em área total de $9,80 \mathrm{~m}^{2}$, com espaçamento de $1,00 \mathrm{~m}$ entre filas e $0,70 \mathrm{~m}$ entre plantas. Os dados foram obtidos de 10 plantas úteis por parcela.

$\mathrm{O}$ leito da sementeira, onde as mudas foram produzidas, foi constituído por uma mistura 1:2:1, de cama de curral, solo fértil e areia, adubada com $100 \mathrm{~g} \mathrm{~m}^{-}$ 2 de superfosfato simples e $30 \mathrm{~g} \mathrm{~m}^{-2}$ de cloreto de potássio. Procedeu-se a semeadura em 07/10/1996. Na sementeira, foram feitas irrigações diárias por aspersão. Aos vinte dias após a emergência, em cobertura, aplicou-se adubação com $10 \mathrm{~g} \mathrm{~m}^{-2}$ de sulfato de amônio e foliar com boro e molibdênio.

Uma semana antes do transplante, a área experimental recebeu, na base, adubação com $1.400 \mathrm{~kg}$ $\mathrm{ha}^{-1}$ de esterco de peru, $100 \mathrm{~kg} \mathrm{ha}^{-1} \mathrm{de} \mathrm{N}, 160 \mathrm{~kg} \mathrm{ha}^{-1} \mathrm{de}$ $\mathrm{P}_{2} \mathrm{O}_{5}, 130 \mathrm{~kg} \mathrm{ha}^{-1}$ de $\mathrm{K}_{2} \mathrm{O}$, localizados nos sulcos e incorporados manualmente (SILVA JÚNIOR, 1987; EMPASC., 1989; COMISSÃO DE FERTILIDADE DO SOLODO RS/SC, 1995).

O transplante foi realizado em 20/11/1996, aos 45 dias após a semeadura, no estágio de 4 a 6 folhas verdadeiras e diâmetro da haste entre $5-10 \mathrm{~mm}$ e altura de $0,15 \mathrm{~m}$. Durante a condução do experimento, foram aplicados $180 \mathrm{~kg} \mathrm{ha}^{-1}$ de $\mathrm{N}$, em cobertura, logo após o pegamento, vinte dias mais tarde, no início da emissão da cabeça e ramificações e duas adubações foliares de boro e molibdênio. Os demais procedimentos fitotécnicos para a produção de mudas e condução do experimento foram os normalmente recomendados para a cultura.

As colheitas foram feitas no período de 27/ 12/1996 a 18/02/1997, com dois repasses semanais. A maturação comercial das cabeças centrais e laterais foi determinada pelos seguintes critérios visuais: cor verde intensa, flores fechadas, botões florais compactos e pedúnculos florais tenros e sem alongamento excessivo (CORREIA, 1983). As cabeças com flores abertas; alongamento de pedúnculos; danos de pragas, doenças e geadas, e ramificações com comprimento inferior a $0,15 \mathrm{~m}$, foram consideradas não comerciais.

As variáveis avaliadas foram o rendimento de cabeças comerciais; rendimento de ramificações comerciais; rendimento comercial, obtido pela soma do rendimento de cabeças e ramificações comerciais; o rendimento total, obtido pela soma do rendimento de cabeças e de ramificações comerciais e não comerciais; período de colheita, obtido pela diferença, em dias, da última e primeira colheita realizada e o ciclo hortícola, em dias, obtido pelo tempo decorrido entre a semeadura e a última colheita.

Os dados foram submetidos à análise de variância e teste $\mathrm{F}$ e utilizou-se o teste de Duncan, a $5 \%$ de probabilidade de erro, para a separação das médias.

\section{RESULTADOS E DISCUSSÃO}

Os resultados obtidos, neste trabalho, revelam aptidão de Santa Maria para o plantio de cultivares de brócolis dos grupos de cabeça central e ramoso, no período de outubro a fevereiro, época também avaliada para a mesma finalidade em outras regiões (TOLEDO, 2001).

Em relação ao rendimento comercial (RCO), obtido pelo somatório dos rendimentos de cabeças (CAC) e ramificações comerciais (RAC) observaramse diferenças significativas entre as cultivares avaliadas (Tabela 1).

A participação percentual da variável rendimento comercial na composição do rendimento

Ciência Rural, v. 33, n. 2, mar-abr, 2003. 
Tabela 1 - Cabeças comerciais (CAC), ramificações comerciais (RAC), rendimento comercial (RCO) rendimento total (RTO), em t ha ${ }^{-1}$, período de colheita, ciclo hortícola, em número de dias, de oito cultivares de brócolis. Santa Maria, 1996.

\begin{tabular}{|c|c|c|c|c|c|c|}
\hline Cultivar & CAC & RAC & $\mathrm{RCO}$ & RTO & $\begin{array}{l}\text { Período de } \\
\text { colheita }\end{array}$ & $\begin{array}{l}\text { Ciclo } \\
\text { hortícola }\end{array}$ \\
\hline Baron & $6,10 a^{1}$ & $4,67 \mathrm{de}$ & $10,77 \mathrm{~cd}$ & $10,80 \mathrm{~cd}$ & 40 & 135 \\
\hline Flórida & $1,82 \mathrm{~d}$ & 6,68 cde & $8,51 \mathrm{def}$ & $8,51 \mathrm{~d}$ & 45 & 135 \\
\hline $\begin{array}{l}\text { Ramoso Santana } \\
\text { (Agroflora) }\end{array}$ & $3,33 \mathrm{bc}$ & $6,24 \mathrm{de}$ & 9,58 cde & $9,90 \mathrm{~d}$ & 31 & 135 \\
\hline $\begin{array}{l}\text { Piracicaba } \\
\text { Precoce de Verão }\end{array}$ & $3,07 \mathrm{bc}$ & $10,45 \mathrm{~b}$ & $13,52 \mathrm{~b}$ & $13,56 \mathrm{~b}$ & 43 & 135 \\
\hline Condor & $2,37 \mathrm{~cd}$ & $4,37 \mathrm{de}$ & $6,74 \mathrm{f}$ & $6,90 \mathrm{e}$ & 37 & 135 \\
\hline $\begin{array}{l}\text { Piracicaba } \\
\text { precoce }\end{array}$ & 2,77 & $13,35 \mathrm{a}$ & $16,12 \mathrm{a}$ & $16,30 \mathrm{a}$ & 48 & 135 \\
\hline $\begin{array}{l}\text { Ramoso Santana } \\
\text { (Isla) }\end{array}$ & $3,40 \mathrm{bc}$ & $6,80 \mathrm{~cd}$ & $10,20 \mathrm{~cd}$ & $10,21 \mathrm{~cd}$ & 32 & 135 \\
\hline Gren River & $3,58 \mathrm{~b}$ & $8,79 \mathrm{bc}$ & $12,37 \mathrm{bc}$ & $12,79 \mathrm{bc}$ & 40 & 131 \\
\hline $\begin{array}{l}\text { Ramoso Santana } \\
\text { (Topseed) }\end{array}$ & 2,94 & $5,28 \mathrm{de}$ & 8,22 def & 8,33 de & 27 & 134 \\
\hline Ramoso Santana & 2,87 & $4,19 \mathrm{e}$ & 7,06 ef & $7,07 \mathrm{e}$ & 27 & 135 \\
\hline Hana Midori & $5,10 \mathrm{a}$ & $4,83 \mathrm{de}$ & $9,93 \mathrm{~cd}$ & $10,13 \mathrm{~cd}$ & 34 & 130 \\
\hline Média & 3,39 & 6,88 & 10,27 & 10,40 & 37 & 134 \\
\hline $\begin{array}{l}\text { Coeficiente de } \\
\text { Variação }\end{array}$ & 21,14 & 22,39 & 17,23 & 16,89 & - & - \\
\hline
\end{tabular}

${ }^{1}$ Cultivares com médias não seguidas por mesma letra, dentro de cada variável, diferem entre si pelo teste de Duncan, em nível de $5 \%$ de probabilidade de erro.

qualitativo foi em média $98,72 \%$ para todas as cultivares, indicando que as condições climáticas prevalecentes durante o período experimental foram favoráveis à diferenciação e desenvolvimento das inflorescências centrais e laterais. 'Florida', 'Piracicaba Precoce de Verão’ e 'Ramoso Santana' (Isla e Agroceres) obtiveram um rendimento comercial de, praticamente, $100 \%$, inferindo-se disto que as temperaturas elevadas que ocorreram durante o ciclo da cultura não coincidiram com os períodos críticos, de sensibilidade acentuada a essa variável climática.

A análise de variância mostrou diferenças significativas entre as cultivares para a variável cabeças comerciais (Tabela 1). A participação percentual da variável rendimento de cabeças comerciais na composição do rendimento comercial foi em média, para todas as cultivares, de $34,3 \%$, tendo a mais alta sido de $56,6 \%$, para a 'Baron', e $17,2 \%$, para 'Piracicaba Precoce'. Os rendimentos de cabeças comerciais de 'Baron' e 'Hana Midori', cujo peso médio foi, respectivamente, de 430 e $359 \mathrm{~g}$, não diferiram entre si e foram estatisticamente maiores que os das demais. A diferença encontrada para a variável rendimento de cabeças comerciais é atribuída ao peso das cabeças, já que $100 \%$ da população de plantas experimentais emitiram inflorescências centrais.

Também houve diferença significativa entre as cultivares quanto à variável rendimento de ramificações comerciais (Tabela 1). A menor e maior participação percentual da variável rendimento de ramificações comerciais na composição do rendimento comercial foi de $43,36 \%$, para 'Baron' e 82,8\%, para 'Piracicaba Precoce'. O rendimento de ramificações de 'Piracicaba Precoce' foi 3,18 vezes maior que o de 'Ramoso Santana' (Agroceres). A variabilidade encontrada para rendimento de ramificações é atribuída ao crescimento das hastes laterais e inflorescências emitidas por planta, as quais determinaram a significância estatística das diferenças detectadas entre cultivares.

Para a variável rendimento total (RTO), houve diferença significativa entre as cultivares (Tabela 1). O máximo rendimento total obtido neste estudo foi 2,36 vezes maior que o rendimento mínimo. O componente rendimento de cabeças centrais contribuiu em maior proporção para o rendimento total de duas cultivares, enquanto que o rendimento comercial de ramificações foi o componente de maior contribuição para o rendimento total de seis cultivares.

O ciclo hortícola foi, em média, de 134 dias para todas as cultivares.

O período de colheita, variou, entre cultivares, tendo sido o menor de 27 dias, para 'Ramoso Santana' (Topseed e Agroceres) e o maior, de 48 dias, para 'Piracicaba Precoce' (Tabela 1). O período de colheita de cabeças e ramificações laterais variou, entre as cultivares estudadas, de 4 a 8 semanas, o que revela comportamento distinto entre elas tanto para desenvolvimento de inflorescências centrais e hastes e inflorescências laterais. As cultivares com menor período de colheita apresentaram rendimento semanal comparativamente mais tardio, e rendimento significativamente menor na produção de ramificações, que outras cultivares ramosas mais precoces. A maior concentração de colheita de brócolis, como afirmam BJÖRKMAN \& PEARSON (1998), tem relação com a uniformidade do desenvolvimento vegetativo das populações, pois a formação dos primórdios florais inicia quando o meristema apical tem diâmetro inferior a $1 \mathrm{~mm}$.

'Baron', 'Hana Midori' e 'Green River', do tipo cabeça central, apresentaram maior precocidade para a variável rendimento de cabeça, acumulando a maior parte deste componente de produção em três

Ciência Rural, v. 33, n. 2, mar-abr, 2003. 


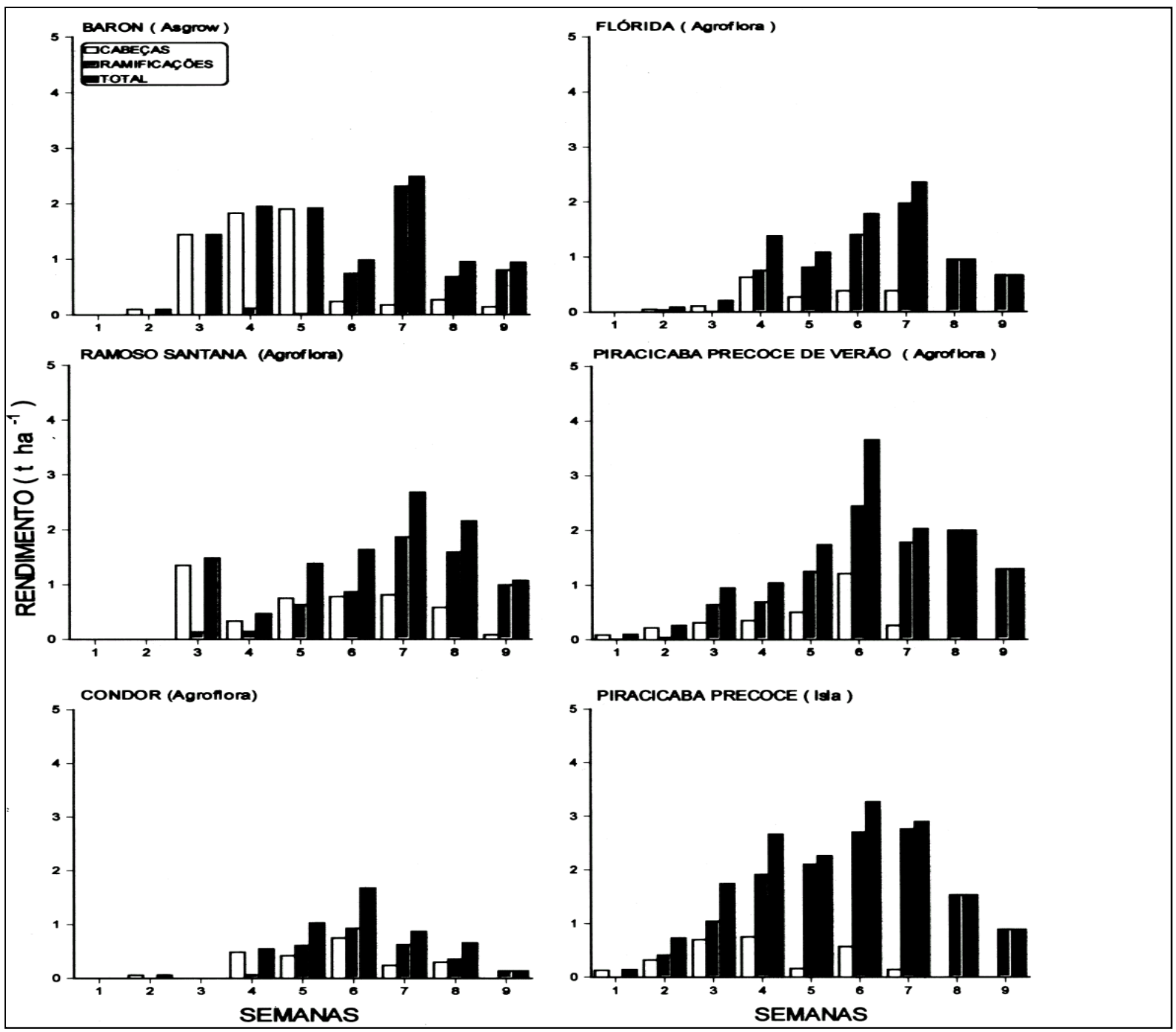

Figura 1A - Distribuição semanal do rendimento comercial de cabeças, ramificações e total ( $\mathrm{t}$ há $\left.{ }^{-1}\right)$ de cultivares de brócolis durante o período de colheita de dezembro, janeiro e fevereiro. Santa Maria, RS, 1996.

semanas do período de colheita (Figura 1A e 1B). As cultivares Baron, e Green River destacaram-se pela precocidade do rendimento de cabeças centrais, embora este tenha sido desprezível nas duas primeiras semanas do período de colheita. Já a cultivar Hana Midori apresentou rendimento nulo nas três primeiras semanas do período de colheita.

A colheita da cabeça central influencia o crescimento das hastes laterais, no ápice das quais se formarão as inflorescências laterais. O rendimento de ramificações comerciais foi o principal componente do rendimento das cultivares Florida, Ramoso Santana (Agroflora, Isla, Topseed e Agroceres), Piracicaba Precoce de Verão, Condor, Piracicaba Precoce e Green River (Tabela 1).

Cinco cultivares obtiveram o máximo rendimento de ramos laterais na sétima semana do período de colheita e apenas uma cultivar obteve-o na sétima semana. A cultivar Ramoso Santana apresentou variação na semana de ocorrência do máximo rendimento semanal em função da procedência da semente. O rendimento semanal das cultivares Ramoso Santana (Isla e Agroceres), Hana Midori e Condor foi nulo ou quase nulo nas três primeiras semanas do período de colheita. 'Piracicaba Precoce de Verão' e 'Piracicaba Precoce' apresentaram pequeno rendimento na primeira semana de colheita, aumentando gradativamente a partir da segunda semana.

\section{CONCLUSÕES}

A variabilidade do desempenho das cultivares estudadas revelou a possibilidade de 


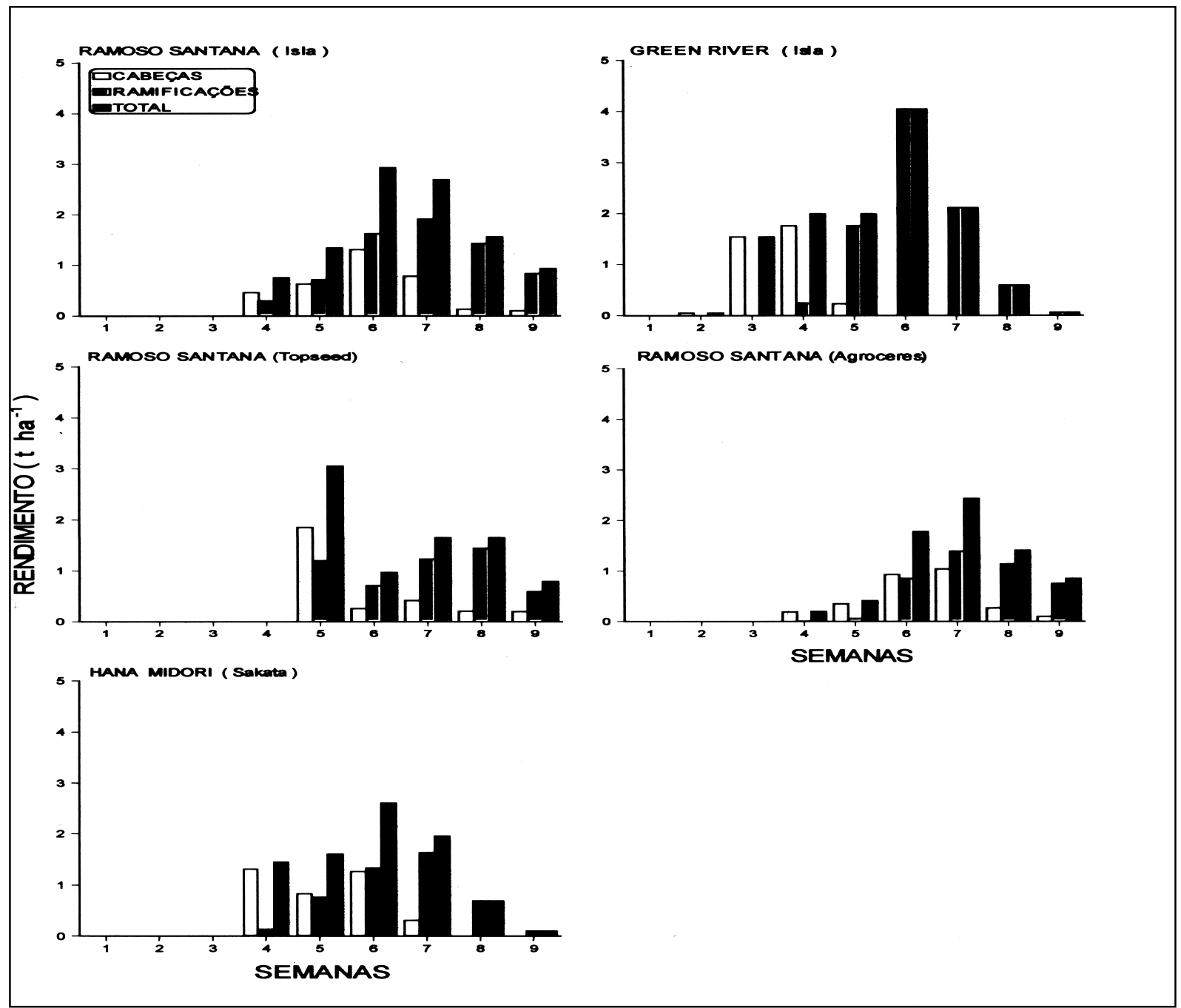

Figura 1B - Distribuição do rendimento comercial de cabeças, ramificações e total $\left(\mathrm{t}\right.$ ha $\left.{ }^{-1}\right)$ de cultivares de brócolis durante o período de colheita de dezembro, janeiro e fevereiro. Santa Maria, RS, 1996

produção de brócolis dos grupos cabeça central e ramoso na região centro do Rio Grande do Sul, com semeadura realizada em outubro. A diferença de rendimento denotou a importância da escolha da cultivar para plantios em escala comercial.

\section{REFERÊNCIAS BIBLIOGRÁFICAS}

ATHANÁZIO, J.C.; SILVA, N. Heterose em couve-brócolos ramoso para o verão. Horticultura Brasileira, Brasília, v.3,n.1, p.12-15, 1985 .

BRASIL. Ministério da Agricultura. Departamento Nacional de Pesquisa Agropecuária. Divisão de Pesquisa Pedológica. Levantamento de reconhecimento dos solos no Estado do Rio Grande do Sul. Recife : Ministério da Agricultura, 1973. 431p. (Boletim Técnico, 30).

BJÖRKMAN, T.; PEARSON, K.J. High temperature arrest of inflorescence development in broccoli (Brassica oleracea var. italica L.). Journal of Experimental Botany, v.49,n.318, p.101-106, 1998.

CASSERES, E. Producción de hortalizas. 3 ed. San José : IICA, 1980. 387p.

COMISSÃO DE FERTILIDADE DO SOLO DO RS/SC. Recomendações de adubação e de calagem para os Estados do Rio Grande do Sul e Santa Catarina. 3 ed. Passo Fundo : SBCS - Núcleo Regional Sul/EMBRAPA/CNPT, 1995. 224p.

CORREIA, L.G. Colheita, classificação, embalagem e comercialização de brássicas. Informe Agropecuário, Belo Horizonte, v.9, n.98, p.52-54, 1983.

DALMOLIN, R.S.D., KLAMT, E. Solos de textura superficial média a arenosa do RS: características, classificação e aptidão de uso agrícola. In: FRIES, M.R.; DALMOLIN, R.S.D. (coord). Atualização em recomendação de adubação e calagem ênfase em plantio direto. Santa Maria : UFSM-SBCS, 1997. p.9-22.

Ciência Rural, v. 33, n. 2, mar-abr, 2003. 
FERREIRA, F.A. Efeito do clima sobre as brássicas. Informe Agropecuário, Belo Horizonte, v.9, n.98, p.12-14, 1983.

FILGUEIRA, F.A.R. Brassicáceas. In: Manual de olericultura: cultura e comercialização de hortaliças. 2 ed. São Paulo : Agronômica Ceres, 1982. 2v. Cap.2, p.33-75.

GIORDANO, L. de B. Melhoramento de brássicas. Informe Agropecuário, Belo Horizonte, v.9, n.98, p.16-20, 1983.

KNOTT, J.E. Handbook for vegetable growers. New York: John Wiley \& Sons, 1962. 245p.

LIRA FILHO, H.P. et al. Competição de cultivares e híbridos de couve-brócolos (Brassica oleracea var. italica L.) na Zona da Mata do Estado de Pernambuco. In: CONGRESSO BRASILEIRO DE OLERICULTURA,37, 1997, Manaus. Horticultura Brasileira... Brasília : SOB, 1997, v.15, suplemento.

McCOLLUM, J.P. Producing vegetable crops. Danville : The Interstate, 1975. 559p.

MELO, P.E. de; GIORDANO, L. de B. Características agronômicas e para processamento de híbridos comerciais e experimentais de couve-brócolos de cabeça única. In: CONGRESSO BRASILEIRO DE OLERICULTURA, 35., 1995, Foz do Iguaçu, PR. Horticultura Brasileira... Brasília : SOB, 1995. v.13, n.1, p.95.
SANTA CATARINA. Secretaria de Estado do Desenvolvimento Rural e da Agricultura. Empresa de Pesquisa Agropecuária e Extensão Rural - EPAGRI. Cultivares catarinenses: um modelo de pesquisa. Agropecuária Catarinense, Florianópolis, v.14, n. 1, p. 2,2001 .

SANTA CATARINA. Secretaria de Estado do Desenvolvimento Rural e da Agricultura. Empresa de Pesquisa Agropecuária e Extensão Rural - EPAGRI. Normas técnicas para a cultura do repolho. Florianópolis : EMPASC/ACARESC, 1989. 26p. (Sistemas de Produção, 13).

SILVA JÚNIOR, A.A. Repolho: fitologia, fitotecnia, tecnologia alimentar e mercadologia. Florianópolis : EMPASC, 1987. 295p.

SILVA, G. Brócolis: o primo rico. Globo Rural, n.143, 1997.

SONNENBERG, P.E. Olericultura especial. 3 ed. Goiânia: Líder, 1985. 149p. 2a Parte. (Mimeografado).

THOMPSON, H.C.; KELLY, W.C. Vegetables crops. 5.ed. Bombay : McGraw-Hill, 1959. 611p.

TOLEDO, L.R. Opção pelo frio. Globo Rural, Jaguaré, ano 16, n.187, p.72-75, 2001.

UNIVERSITY OF CALIFORNIA. Integrated pest management for cole crops and lettuce. Berkeley : Division of Agriculture and Natural Resources, 1987. 112p. 